\title{
Literatura, sexo e doenças: novas narrativas sobre o Império Inglês
}

\section{Literature, sex, and diseases: new narratives on the British Empire}

\author{
Cláudio DeNipoti \\ Professor associado do Departamento de História/Universidade Estadual de Ponta Grossa \\ R. Dr. Faivre, 319/303 \\ 80060-020 - Curitiba - PR - Brasil \\ denipoti@ig.com.br
}

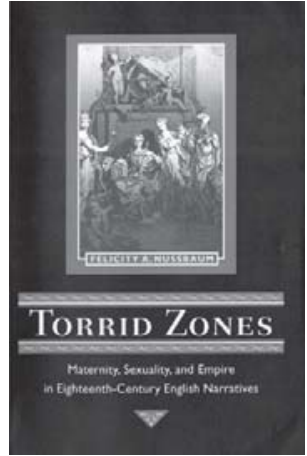

Nussbaum, Felicity A. Torrid zones: maternity, sexuality, and Empire in eighteenth century English narratives. Baltimore: Johns Hopkins University Press. 1995. 248p.

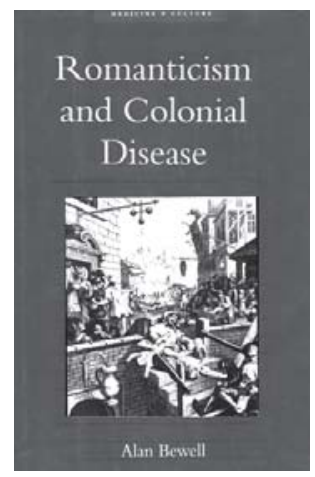

Bewell, Alan. Romanticism and colonial disease. Baltimore: Johns Hopkins University Press. 1999. 374p.
$P^{3}$ assadas quase três décadas desde que Lawrence Stone (1979) publicou seu controverso artigo sobre o retorno da narrativa, no qual indicava algumas tendências da escrita da história, tal como a sua proximidade com estilos literários de narração, a preocupação dos historiadores com relação à literatura parece ter esbarrado em uma encruzilhada metodológica que oferece duas opções: uma, que busca ver a literatura como fonte para a escrita da história, principalmente a partir da ruptura da dicotomia entre fato e ficção oferecida pela epistemologia da história cultural (Chartier, 1988); e outra, que busca na narratividade literária uma forma de expressão discursiva, cujas "oposições ontológicas e epistemológicas ... conduzem a determinadas posturas ideológicas e também especificamente políticas" (Villavicencio, 2007, p.85). Em geral, com as exceções de praxe, a primeira postura tende a menosprezar os aspectos comunicativos da literatura, em particular as práticas derivadas da leitura, ao passo que a segunda reduz a literatura a protocolos linguísticos, sem considerar as delimitações sociais, temporal e geograficamente construídas, que regem a produção de qualquer tipo de conhecimento (Chartier, 1998, p.257).

Porém, trabalhos devotados à percepção da realidade 'através' de obras literárias (ou seja, que buscam na literatura formas de estruturação discursiva de processos sociais historicamente construídos) têm sido sistematicamente produzidos - ainda que não tenham sido traduzidas no Brasil - ao longo das décadas pelas quais o debate se arrasta. Nesses trabalhos, as narrativas literárias são consideradas instrumentos para a realização de estudos hermenêuticos, sem necessariamente se prender ao debate linguístico por si só. Trata-se de trabalhos que buscam incluir os tropos literários em processos culturais mais amplos.

Busca-se aqui identificar, em duas obras que são sintomáticas dessas questões, alguns percursos metodológicos que avançaram a 
prática historiográfica realizada a partir das relações possíveis entre história e literatura. Os livros de Felicity Nussbaum, Torrid zones: maternity, sexuality, and Empire in eighteenth century English narratives, e o de Alan Bewell, Romanticism and colonial disease, estão consolidados na historiografia de língua inglesa sobre o império britânico e oferecem abordagens inovadoras sobre as relações entre a construção de imagens literárias e sociais, nos temas recortados pelos autores.

O livro de Nussbaum é difícil de qualificar, do ponto de vista das convenções acadêmicas, já que circula nas margens e nos pontos de encontro de disciplinas como antropologia, psicologia, crítica literária e história, servindo simultaneamente como síntese e modelo de um trabalho multidisciplinar. Mas, para todos os efeitos, é um estudo histórico bastante competente das representações literárias sobre a mulher e o império. São esses dois aspectos que tornam a obra cativante. As representações femininas na literatura inglesa do século XVIII têm uma dupla significação: construir a imagem da mulher ideal e construir a imagem do império a ser submetido e dominado pelos ingleses. O exotismo das colônias servia como contraponto à feminilidade europeia, uma vez que permitia a clara demarcação - e fetichização - do Outro.

O principal argumento da autora é que, no século XVIII, a mulher, "como outros territórios coloniais, é tratada como algo a ser definido, mapeado, testado, explorado e dominado. Metáforas de sedução, penetração e conquista permeiam a linguagem do colonialismo para domar o exótico selvagem e a sexualidade imaginariamente descontrolada do Outro" (p.74). Para isso, ela analisa a produção de obras inglesas de ficção escritas no século XVIII, estabelecendo comparações discursivas entre esses conjuntos de campos. As personagens femininas dessa literatura - amplamente masculina em sua autoria, mas que inclui também as obras de Lady Montagu e de Mary Wollstonecraft - possibilitam a percepção pela autora da construção do Outro, passando necessariamente pela definição identitária do 'nós', neste caso, pela definição da mulher britânica em oposição à mulher das colônias, ou das 'zonas tórridas' - título cuja multiplicidade de sentidos, por si só, indica os caminhos pelos quais a trama do livro se enreda.

Os temas são recortados nas obras escolhidas pela autora para abarcar os diversos aspectos possíveis dessas construções simbólicas. É o caso, por exemplo, do uso que ela faz do livro Life of Savage, publicado por Samuel Johnson em 1744 e baseado na autobiografia que o poeta Richard Savage publicara anonimamente em 1727. Nussbaum analisa, por meio desse livro, a idealização do papel materno. A biografia de Savage (marginalizado por sua origem bastarda e cuja mãe - nobre - se afastara sem reconhecê-lo como filho) frequentemente associa, no texto, essa mãe inglesa com outras mães 'selvagens' - e o duplo sentido do nome do poeta é revelador -, descritas pela literatura como um Outro antropológico, semelhante às mães europeias no tocante às características "naturais" da maternidade, mas simultaneamente dotadas de diferenças fundamentais:

como a mãe inglesa, ela também é simultaneamente adulada e considerada incompetente, ainda que com consequências materiais diferentes. Em vez de ser meramente deslocada, ela é escravizada e silenciada. Ela é o pior e o melhor da "natureza", supostamente capaz de comer, matar ou dar sua criança. Ela supostamente sente pouca dor ao dar a luz ... . Mas ela também tipifica uma mãe mais gentil, ainda não corrompida pelas exigências da cultura. A categoria 
"natural" envolve versões incompatíveis da mãe como nutriz ideal, inocente e pastoral, como primordialmente violenta, erótica e primitiva, como zelosa instintiva e civilizadora dos homens. As tensões que resultam dessa tentativa de manter mães "nativas", inglesas e animais dentro do mesmo quadro de pressupostos sobre os sentimentos maternais pode ser lido para revelar a lógica das relações de gênero e o eurocentrismo durante o Iluminismo (p.51).

De forma semelhante, pela comparação das descrições de viagens à África com a obra Pamela de Samuel Richardson, originalmente publicada em 1740, Nussbaum busca as imagens criadas em torno do tema da poligamia - que funcionam, nessas narrativas, "tanto como uma fantasia masculina quanto como um argumento de racionalidade econômica para lidar de maneira eficaz com as mulheres 'excessivas'” (p.81). Em Pamela a poligamia está associada ao adultério masculino e a imagem da protagonista, a um culto da domesticidade. A relação com o Império é visualizada nas posturas contraditórias manifestas na literatura de viagem, que buscam interpretar a poligamia para, fundamentalmente, combatê-la, tanto em sua forma institucional, frequente e abertamente associada à pornografia e à prostituição (que recorrentemente é exemplificada na literatura por meio de associações com o harém otomano, como é também o caso de Fanny Hill de John Cleland), quanto nas práticas cotidianas ligadas ao adultério.

Assim como esses, outros aspectos da dominação da sexualidade feminina como parte do processo colonial são analisados, indo, como visto, do papel materno à pornografia, passando pelo erotismo do véu e do rubor - polos distintos de um mesmo universo sexual, já que o primeiro impede que se conheça o segundo, que é, nessas representações, compreendido como sinal inegável de virtude. Segundo a autora,

a invenção da "Outra" mulher do Império capacitava a consolidação do culto da domesticidade na Inglaterra e, ao mesmo tempo, a associação da mulher sexualmente transgressiva em casa - a prostituta, a lésbica, o ser assexual - com a mulher exótica orientalizada. No emergente imperativo nacional para controlar a sexualidade feminina e a maternidade de modos particulares, esses textos fornecem resistências àquele imperativo ao reafirmar prazeres alternativos ... (p.160-161).

Permeando a pesquisa e a análise hermenêutica da literatura e dos relatos de viagem, nas quais a autora busca entender como esses textos funcionavam em seus contextos, há a intenção de questionar e desconstruir as formas como o Iluminismo é compreendido na prática historiográfica e, em especial, na atuação feminista. Seguindo as ideias de Michel Foucault, Nussbaum não tenta conservar a herança do Iluminismo, mas sim manter em mente a "própria questão desse evento [o Iluminismo] e seu significado, a questão da historicidade do pensamento do universal" (p.198). É nesse contexto que o livro em foco surge como um todo sistêmico, sobre as "várias instâncias da maternidade e sexualidade" nas quais se percebe que "a caracterização da mulher inglesa como 'outra'" na literatura "é frequentemente destinada a ampliar sua própria independência e construir uma subjetividade mais coerente às custas das várias mulheres do Império" (p.200).

A crítica feminista de que o Iluminismo europeu esteve intimamente associado ao racismo, já que os direitos democráticos pelos quais se lutava na metrópole excluíam $a$ priori "trabalhadores, os povos das colônias e as mulheres" (p.206), foi devidamente incorporada pela autora, fazendo com que a parte final do livro assuma ares de libelo, sem 
que, de forma alguma, comprometa o trabalho, uma vez que a própria autora relativiza tais afirmações. O que emerge das páginas de Torrid zones é um estudo sobre história e literatura com um recorte sobre a imagem feminina, em uma narrativa cativante, capaz de desvelar construções discursivas ao mesmo tempo em que encanta o leitor contemporâneo com uma narrativa própria, fluente, incitante e provocativa.

Alan Bewell consegue efeito semelhante em seu Romanticism and colonial disease, principalmente porque também escreve no limite de disciplinas diversas - neste caso, circulando pela literatura, geografia e história da medicina. Bewell abre a obra apresentando a "Guerra dos mundos", de H.G. Wells, como uma metáfora do avanço colonial como contágio: uma força tecnologicamente superior derrota por completo a quem invade, alterando o meio ambiente segundo suas próprias necessidades ou concepções, mas é derrotada por patógenos aos quais não tem resistência. Nesse sentido, argumenta o autor que "a geografia médica teve um papel primordial na construção da noção de sentir-se, ou sentir ao outro, como estrangeiro. Durante esse período [final do século XVIII até meados do século XIX], 'os trópicos' emergiram como uma construção biomédica original" (p.18)

Nessa lógica, o autor busca estudar como a doença e sua disseminação eram percebidos como fenômenos geográficos e controlados, por meio de localização e "mapeamento dos 'lugares insalubres' em uma região, um país ou através do globo", para que fossem evitados, ou através da construção e interpretação das paisagens, visando identificar que aspectos do ambiente produziam 'ares perigosos', responsáveis pelas doenças segundo as crenças científicas vigentes (p.31).

Vendo a doença como essencialmente geográfica, um problema de locais, mais do que de pessoas, a medicina colonial forneceu uma poderosa alavanca ideológica para a expansão europeia. Já que as regiões coloniais eram amplamente vistas como ambientes "doentes" que precisavam de cura, a geografia médica fornecia uma ratio científica para tornar as ecologias coloniais mais parecidas com aquelas da Europa, introduzindo assim métodos europeus de uso da terra, de organização social e de gerenciamento de recursos. A colonização dos corpos procedia assim da, e era apoiada pela, colonização médica do espaço físico. Se os povos coloniais eram doentes, eles podiam ser curados por mudanças ambientais (p.34).

Assim foi possível pensar os trópicos: essencialmente susceptíveis à transformação, desde muito cedo no projeto colonial britânico. A ideia de que pântanos e florestas, responsáveis pelas doenças, podiam, eles mesmos, ser curados, acompanha a literatura médica do período, como resultado direto da patologização de grandes áreas do globo incutidas na ideia de 'medicina tropical'.

A medicina ambiental europeia justificava, assim, a introdução de métodos europeus de cultivo da terra em outras regiões do mundo. O colono que abrisse uma clareira na mata ou na floresta tropical, ou o imigrante que colocasse a terra sob o arado, drenasse um banhado, ou cercasse um pedaço de terra não estava simplesmente trabalhando para seu próprio benefício econômico, mas também era o agente pelo qual uma terra doente, sem melhorias, seria curada de suas doenças endêmicas (p.40).

O objetivo do autor é mostrar que as construções geográficas da saúde relativa à Inglaterra eram também discursivas. Assim, através da análise da literatura romântica, tanto nas vertentes de apoio quanto de crítica ao nacionalismo e imperialismo ingleses, propõe que 
o "colonialismo era um discurso geográfico sobre saúde e doença e sobre os méritos relativos de ambientes sociais" (p.46).

As relações entre literatura e história surgem quando Bewell analisa a poesia como instrumento de fixação discursiva para esse discurso geográfico. Os poemas "The ruined cottage" (publicado em 1797) e "The brothers" (1798), de William Wordsworth, demonstram como essas relações de doença e paisagem se manifestam no jogo de afastamento e retorno ao território familiar. No primeiro poema, a ruína trazida à família com a ida do marido/ pai para as guerras coloniais tem como principal sintoma a paisagem adoentada pela falta de cuidados. No segundo, irmãos separados pelo esforço colonial constroem relações de estranhamento mútuo quando têm que lidar com partidas e retornos, tornando-se "uma reflexão contraditória sobre a sociedade rural britânica em uma era de viagens comerciais" (p.62), que reflete as experiências da família do próprio Wordsworth, cujo irmão estava envolvido no comércio colonial e distanciava-se - identitariamente - daqueles que permaneciam na metrópole.

Se, por um lado, a permanência na Inglaterra gerava paisagens doentias pelo abandono, por outro a geografia da doença nas colônias provocava discursos mais efusivos, no tocante ao custo epidemiológico da colonização. As narrativas militares coloniais sobre a doença fornecem a Bewel o material bruto com o qual pode perceber os elementos componentes desse custo. $\mathrm{O}$ autor recorre a relatos como a Narrative of a five years expedition against the revolted negroes of Surinam (de 1796), de John Gabriel Stedman - que identifica e sugere repetidamente terem sido a escravidão e o serviço militar nas colônias "quase idênticos [pois] ambos são estruturados em uma enorme perda de vidas, pela perda da liberdade e pela falta de justiça social" (p.93). Recorre também aos poemas "The rime of the ancient mariner" (1797-1799), de Coleridge, "Salisbury plain" (1793-1794) e "The discharged soldier" (1799), de Wordsworth, para buscar as construções discursivas médicas que associavam a doença nas colônias à punição pelos crimes do imperialismo. Ao mesmo tempo, utiliza-se dos poemas para perceber como o discurso político e militar estabelecia uma relação íntima entre doença colonial e vagabundagem: "Se sobrevivessem ao serviço militar, soldados e marinheiros frequentemente voltavam para a Inglaterra como inválidos ou vagabundos, uma fonte contínua de ansiedade para os proprietários. Com medo de que esses homens fossem propensos à violência, os governos com frequência permitiam que eles mendicassem para chegar em casa, se ainda houvesse uma" (p.114).

Bewell tenta ler o colonialismo através dos militares europeus e suas experiências com a doença. Ainda que estas não tenham sido homogêneas, sua percepção foi estruturada de formas múltiplas ao redor de questões de classe ou nacionais. O ponto central é que o colonialismo foi "frequentemente lido como um discurso do Outro apoiado na construção cultural e biométrica de 'outras' raças e povos. A história dos militares coloniais demonstra que aqueles que colonizaram não estavam imunes a tal processo de criação do Outro" (p.128).

Buscando ver outra faceta do mesmo polígono, ao lidar com as ansiedades da dieta colonial, Bewell indica que, como discurso geográfico, o discurso colonial desenvolveu uma poderosa "geografia dietária", com inflexões sobre três tipos de discurso em torno da doença, o político, o antropológico e o médico: "Comer era compreendido intrinsecamente 
como um evento geográfico, uma vez que as ideias sobre quem se é e o que se come estavam ligadas às preocupações sobre onde se come. Uma afirmação de identidade biológica e cultural, a dieta em um contexto cultural era um negócio complicado, dificilmente separável de debates imaginativos e sociopolíticos mais amplos relativos à expansão territorial e à ansiedade que a acompanhava" (p.134).

Por um lado, as imagens literárias tendem a afirmar identidades nacionais em termos alimentares - os revolucionários franceses são representados como canibais famélicos, e a definição de aveia em pelo menos um dicionário inglês reafirma isso: "um grão, que na Inglaterra é geralmente dado para os cavalos, mas na Escócia sustenta o povo" (p.149). Por outro, o alcance do Império é expresso no consumo de produtos de origem colonial como café, chocolate, açúcar e chá. No mesmo passo, a alimentação em um contexto colonial tende a ameaçar as identidades biológicas e culturais. A geografia colonial força a construção de discursos médicos sobre a alimentação, em termos tanto da necessidade de adaptação quanto da recusa em abandonar padrões europeus, denotando o profundo vínculo entre dieta e doença. Isso gerou alto grau da ansiedade, principalmente entre os românticos ingleses, com relação à alimentação - e à doença. O autor verifica isso ao estudar a poesia de John Keats com relação a uma "geografia do consumo", relacionada à experiência imperial e à própria "figura híbrida" do poeta, cuja relação com a tuberculose "constituía um equivalente ocidental do sati [o suicídio indiano ritual da esposa, que se atira à pira do marido morto]: o corpo doente do poeta é a viúva que é consumida pelo fogo dentro dele" (p.193). Isso significa, para Bewell, que a morte de Keats, em 1821, "exerceu uma forte influência na imaginação dos vitorianos e ocupou um lugar central na história das reapresentações europeias do século XIX sobre a doença" (p.184).

Outro exemplo da ansiedade romântica imperial é visto através da poesia de Joseph Ritchie, oficial inglês que descreveu sua própria experiência africana, desde a decisão de partir da Inglaterra até as vésperas de sua morte por disenteria e malária, entrando para a categoria dos europeus que, nos trópicos, "tinham uma leve dose de febre de vez em quando, e um dia, por nenhuma razão extra-aparente, morriam em um acesso adicional de febre" (p.204). Da mesma forma pensa-se a poesia de Percy Shelley, que estabeleceu uma conexão íntima entre a geografia médica e o imperialismo europeu, reconhecendo que a relação entre doença e meio ambiente deveria também ser pensada inteiramente em termos sociais: "Shelley mudou o foco da terapia ... na direção do reconhecimento de que a principal razão pela qual um povo pode sofrer doenças às quais outros são amplamente imunes tem menos a ver com clima ou geografia do que com as relações sociais, os comportamentos humanos e a economia" (p.240-241).

Todas as análises de Bewell - que incluem as representações coloniais da Índia na poesia romântica inglesa e o romance de Mary Shelley, The last man, que descreve a extinção da raça humana pela doença, em meados do século XXI - auxiliam a construção das visões contraditórias que o Império construiu sobre a doença, colocando questões até hoje válidas: "a sociedade constitui uma defesa contra as epidemias? Quanto pode um Estado bem responder a um aumento da doença, quando seus recursos são limitados?". Que novas doenças são transportadas pelo planeta? (p.304-307). As conclusões do autor são que a literatura romântica catalisou as ansiedades europeias diante dos impérios. H.G. Wells cita 
a obra de Mary Shelley em Guerra dos mundos, já que ambos os livros registram "imaginativamente uma experiência coletiva que frequentemente não deixava registros" (p.307), vendo a doença colonial dar o troco aos colonizadores, fornecendo uma leitura da metrópole colonial a partir da perspectiva da periferia.

O que aproxima as obras de Nussbaum e Bewell? Em primeiro lugar, a noção ampliada de Império, presente em ambos os textos, permite perceber uma associação íntima entre colonialismo, Iluminismo e modernidade, sem cair em visões teleológicas tendentes a construir uma narrativa que demonstra um caminho inexorável desde o século XVIII até essa mesma modernidade. Da mesma forma, as duas obras buscam romper com a dicotomia que vê o imperialismo simplesmente ligado ao domínio político e econômico, ao passo que o colonialismo diria respeito exclusivamente à ocupação e mudança total da sociedade colonizada. Na verdade, Nussbaum e Bewell questionam essas narrativas e suas conjunções com a ideia hodierna de globalização, "reavaliando a natureza problemática dessa herança" no Ocidente (Nussbaum, 2003, p.3). Os autores percebem que as epistemologias pósmodernas não são adequadas para a compreensão das estratégias de negociação de identidades no passado, ainda que elas se apresentem como tropo narrativo.

Em segundo lugar, a narrativa literária é um instrumento de trabalho para os dois historiadores (na análise hermenêutica e na prática da escrita), pois eles não se perdem em prolegômenos relativos aos imperativos linguísticos. Em outras palavras, os tropos literários caracterizam (também) processos mentais expressos em outras práticas culturais, além da literatura ou da poesia, e não são um fim em si próprios.

Outros estudos posteriores reafirmam essas posições e abordagens, como o de Rod Edmond, que apresenta o conceito de 'reencontro' para "descrever o modo como viajantes ingleses do século XVIII revisitaram" as ilhas do Pacífico e lidaram com os "efeitos cumulativos" das visitas anteriores. Interessam ao autor as visões construídas sobre as doenças levadas pelos europeus, que deixaram marcas nas peles dos nativos, transformandoas na "superfície sobre a qual o contato cultural foi escrito" (Nussbaum, 2003, p.16-17; Edmond, 2003). Ou ainda o estudo de Jill Casid (2003) sobre a introdução de plantas exóticas em solos coloniais, entendida como conquista agrícola nas narrativas ficcionais do século XVIII, nas quais os próprios personagens - como Robinson Crusoe, ou os protagonistas de Paul et Virginie - "assumem as características das plantas, seus corpos servindo para fertilizar e, no limite, reproduzir o Império na forma de um jardim global harmoniosos", através do qual o Império assume corpo físico na paisagem colonial (Nussbaum, 2003, p.17).

Por fim, ambos os estudos partem da ideia de que as verdades plenamente estabelecidas são em geral construídas de modo etnocêntrico, que pode, por sua vez, ser entendido como "o modo profundamente enraizado e universalmente disseminado de preencher as diferenças entre o eu e os outros com valores positivos e negativos" (Rüsen, 2004, p.120). Esses trabalhos enfatizam a necessidade de reinterpretar continuamente o próprio conhecimento historiográfico, de modo a desafiar essas verdades. 


\section{REFERÊNCIAS}

CASID, Jill.

Inhuming Empire: islands as colonial nurseries and graves. In: Nussbaum, Felicity (Ed.). The global eighteenth century. Baltimore: The John Hopkins University Press. p.279-291. 2003.

CHARTIER, Roger.

Writing the practices. French Historical Studies, v. 21, n.2, p.255-264. 1998.

CHARTIER, Roger.

História cultural: entre práticas e representações. Lisboa: Difel. 1988.

EDMOND, Rod

Island transactions: encounters and disease in the South Pacific. In: Nussbaum, Felicity, (Ed.). The global eighteenth century. Baltimore: The John Hopkins University Press. p.251-262. 2003.
NUSSBAUM, Felicity A. (Ed.).

The global eighteenth century. Baltimore: The John Hopkins University Press. 2003.

RÜSEN, Jörn.

How to overcome ethnocentrism: approaches to a culture of recognition by history in the twenty-first century. History and Theory, Middletown, theme issue 43. p.118-129. 2004.

STONE, Lawrence.

The revival of narrative: reflections on a new old history. Past \& Present, Oxford, v.85, n.1, p.3-24. 1979.

VILLAVICENCIO, Herminio Nuñes.

Narración histórica y narrativa literaria, una cuestión posmoderna. Ciencia Ergo Sum, Toluca, v.14, n.1, p.81-92. 2007. 